\title{
Produção integrada de aquaponia e digestão anaeróbica para geração de biogás em meio urbano
}

O sistema integrado entre aquicultura, hidroponia e dejeto bovino apresenta soluções ambientalmente viáveis para produção de alimentos e energia no meio urbano. Os biodigestore anaeróbios são compostos por câmara hermética, na qual sob condições ideais de operação permitem que bactérias degradem os resíduos orgânicos presentes no sistema. 0 biogás gerado a partir deste, pode ser utilizado como combustível, com uso em turbinas, motores a gás e caldeiras para produção de energia elétrica. Dessa forma, objetivou-se avaliar a substituição da água no processo de digestão anaeróbica do dejeto bovino pelo lodo de piscicultura. O experimento foi conduzido no Laboratório de Eletrificação Rural e Energias Alternativas do Departamento de Engenharia da UFRRJ. Utilizaram-se protótipos de biodigestores anaeróbios de bancada no modelo indiano, sendo o sistema de abastecimento a batelada. Os substratos utilizados nos processos de monodigestão anaeróbica e codigestão anaeróbica foram o lodo de piscicultura (LP) e dejeto de bovino (DB), nas concentrações de 100:0, 75:25, 50:50, 25:75 e utilizados nos processos de monodigestão anaeróbica e codigestão anaeróbica foram o lodo de piscicultura (LP) e dejeto de bovino (DB), nas concentrações de 100:0, $75: 25,50: 50,25: 75$ e 0:100 LP:DB. Por meio da realização do teste de queima do biogás, para detecção de presença ou não de metano, em quantidade suficiente para manter a chama, confirmou-se a presença
de biogás a partir da terceira semana. Os modelos matemáticos Sigmoide de Boltzmann para as relações 75:25 e 0:100 LP:DB e Gompertz para 50:50 e 25:75 LP:DB foram considerados os melhores para estimar as curvas de cinética de produção acumulada de biogás. A relação 25:75 LP:DB apresentou maior valor de produção acumulada de biogás, sendo de 13,55 L em 16 semanas. O potencial de produção acumulada, demonstrou aproveitamento superior a 90\% da eficiência energética para combustíveis fosseis comparado a relação 0:100 LP:DB. Portanto, conclui-se que o lodo de piscicultura ofereceu melhorias na codigestão anaeróbica em relação a monodigestão anaeróbica, sendo um substrato de grande importância para a geração de energia na produção de biogás. Ao realizar a substituição de um bem nobre como a água, tornou-se um sistema sustentável nos pilares das dimensões social, econômica e ambiental adequado.

Palavras-chave: Piscicultura; Hidroponia; Energia; Biodigestor anaeróbico; Modelagem matemática.

\section{Integrated aquapony production and anaerobic digestion for biogas generation in urban environment}

\begin{abstract}
The integrated system between aquaculture, hydroponics and cattle manure can present environmentally viable solutions for the production of food and energy in the urban environment. Anaerobic biodigesters are composed of a hermetic chamber, in which, under ideal operating conditions, they allow bacteria to break down organic waste present in the system. The biogas generated from it can be used as a fuel, used in turbines, gas engines and boilers to produce electricity. Thus, the objective was to evaluate the replacement of water in the process of generated from it can be used as a fuel, used in turbines, gas engines and boilers to produce electricity. Thus, the objective was to evaluate the replacement of water in the process of
anaerobic digestion of cattle manure by fish farming sludge. The experiment was carried out at the Rural Electrification and Alternative Energy Laboratory at the Engineering Department of anaerobic digestion of cattle manure by fish farming sludge. The experiment was carried out at the Rural Electrification and Alternative Energy Laboratory at the Engineering Department of digestion processes were fish farming sludge (FS) and cattle manure (CM), in ratios of 100:0, 75:25, 50:50, 25:75 and 0:100 FS:CM. By carrying out the biogas-flaring test to detect the presence or absence of methane in sufficient quantity to maintain the flame, biogas was confirmed from the third week. Boltzmann's Sigmoid mathematical model for the 75:25 and 0:100 FS:CM ratio and the Gompertz mathematical model for 50:50 and 25:75 FS:CM ratios were considered the best ones to estimate the kinetic curves of accumulated biogas production. The $25: 75 \mathrm{FS}: \mathrm{CM}$ ratio showed the highest accumulated biogas production value, being $13.55 \mathrm{~L}$ in 16 weeks. The cumulative biogas yield, demonstrated use of more than $90 \%$ of the energy efficiency for fossil fuels compared to the ratio 0:100 FS:CM. Therefore, it is concluded that the fish farming sludge offered improvements in anaerobic co-digestion in relation to anaerobic mono-digestion being a substrate of great importance for the generation of energy in the biogas production. When replacing a noble good such as water, it became a sustainable system on the pillars of the appropriate social, economic and environmental dimensions.
\end{abstract}

Keywords: Pisciculture; Hydroponics; Energy; Anaerobic digester; Mathematical modeling.

Topic: Engenharia da Sustentabilidade e Meio Ambiente

Reviewed anonymously in the process of blind peer.
Received: 06/03/2021

Approved: 22/03/2021
Luiza Maria Affonso Silva (i)

Universidade Federal Rural do Rio de Janeiro, Brasil http://lattes.cnpq.br/3849420192121956 http://orcid.org/0000-0003-2705-1396 luizaaffonso3@gmail.com

\section{Juliana Lobo Paes (iD)}

Universidade Federal Rural do Rio de Janeiro, Brasil http://lattes.cnpq.br/8567579362150921 http://orcid.org/0000-0001-9301-0547

juliana.lobop@gmail.com

Frederico Alan de Oliveira Cruz (iD)

Universidade Federal Rural do Rio de Janeiro, Brasil http://lattes.cnpq.br/7657422977567514

http://orcid.org/0000-0002-2612-3952

frederico@ufrri.br

DOI: 10.6008/CBPC2179-6858.2021.003.0036

\author{
Beatriz Costalonga Vargas (iD \\ Universidade Federal de Viçosa, Brasil \\ http://lattes.cnpq.br/8731372184121178 \\ http://orcid.org/0000-0002-2612-447X \\ beatriz.vargas@ufv.br \\ Vinicius Rocha Pereira (id) \\ Universidade Federal Rural do Rio de Janeiro, Brasil \\ http://lattes.cnpq.br/4369487148832102 \\ http://orcid.org/0000-0002-1733-6163 \\ vinirp.04@gmail.com \\ Maxmillian Alves de Oliveira Merlo (iD) \\ Universidade Federal Rural do Rio de Janeiro, Brasil \\ http://lattes.cnpq.br/0441362832503764 \\ http://orcid.org/0000-0002-9619-4000 \\ maxmerlo2@hotmail.com
}

\section{Referencing this:}

SILVA, L. M. A. L.; PAES, J. L.; CRUZ, F. A. O.; VARGAS, B. C.; PEREIRA, V. R.; MERLO, M. A. O.. Produção integrada de aquaponia e digestão anaeróbica para geração de biogás em meio urbano. Revista Ibero Americana de Ciências Ambientais, v.12, n.3, p.440-457, 2021. DOI: http://doi.org/10.6008/CBPC2179-6858.2021.003.0036 


\section{INTRODUÇÃO}

A produção de alimentos e a necessidade de água potável para abastecer a população mundial e o setor produtivo é um dos grandes desafios que devem ser enfrentados pelos diversos países do mundo no século XXI. Atualmente, $55 \%$ da população mundial residente em ambientes urbanos, com estimativa de aumento de cerca de $60 \%$ na próxima década (FAO, 2019). Essa realidade em que gera a necessidade de localizar a vertente produtiva nas áreas intra-urbanas, acarretou no modelo denominado como Agricultura Urbana. Além de suprir a necessidade de alimentos para as populações urbanas, esse sistema de produção tem como característica básica impactar diretamente as pessoas envolvidas e na mudança dos espaços urbanos. Dentre as ações empregadas, cita-se a (re)educação ambiental pelas atividades de práticas sustentáveis, estímulo ao engajamento social de comunidades marginalizadas, impactando diretamente na geração de empregos, consequentemente no combate da pobreza dos indivíduos dessas regiões pela ocupação laboral, e não menos importante com a valorização da cultura local (BATITUCCI et al., 2019). Em complemento, tem-se o aproveitamento de espaços, públicos ou privados, em condições de abandono, que deixam de ser um local propício para a geração de impactos negativos a saúde pública, por ser um ambiente propício a proliferação de vetores de doenças, para se tornar um espaço produtivo.

O modelo de produção baseado na Agricultura Urbana aproxima o Brasil da política global Agenda 2030 para o Desenvolvimento Sustentável (SEIXAS et al., 2020), a qual estabelece 17 Objetivos do Desenvolvimento Sustentável (ODS). No Brasil, a Agricultura Urbana se inseriu a partir do Programa Fome Zero em 2001, do Governo Federal, que teve como objetivo assegurar o direito humano à alimentação adequada às pessoas com dificuldades de acesso aos alimentos. $O$ referido programa gerou algumas ações importantes, como a criação do Programa de Agricultura Urbana e Perirubana (BRASIL, 2010) e dos projetos Hortas Comunitárias, Programa de Verticalização da Pequena Produção Agropecuária, Projeto de Formação de Agentes de Desenvolvimento Local em Segurança Alimentar Nutricional e Agricultura Urbana e o Projeto Cinturão Produtivo, Preservando e Alimentando a Cidade (BATITUCCI et al., 2019).

Dentre as práticas adotadas pela Agricultura Urbana, tem-se a aquaponia, que integra os sistemas de piscicultura semi-intensivo e hidroponia, de forma sustentável e menos impactante ao meio ambiente. A sinergia desses sistemas consiste na utilização eficiente da água para a produção de alimentos, recirculação do efluente da aquicultura, o qual, provavelmente, seria despejado em corpos d'água a jusante e reutilização biofertilizante na cultura (BUSS et al., 2015; HUNDLEY et al., 2013; MARISCAL-LAGARDA et al., 2012). Isto é, tem-se adoção de sistema integrado de produção visando a abordagem do conceito de economia circular, em que prega redução, reutilização, reciclagem e recuperação de materiais nos processos de extração, produção, distribuição e consumo destes (VANDER et al., 2019).

No sistema de aquaponia, são instalados filtros ou biofiltros, para auxiliar na qualidade da água tanto de recirculação quanto residual. Além disso, preserva e adequa nas legislações vigentes à produção do sistema de aquicultura. A água residual, após o tratamento, necessita atender as legislações da resolução do CONAMA № 413, de 26 de junho de 2009, em que dispõe sobre o licenciamento ambiental da aquicultura. 
No entanto, há geração de lodo de piscicultura composto por restos sólidos de ração, dejetos de peixes, colônias mortas de bactérias e algas filamentosas, caracterizando-o com elevada concentração de matéria orgânica (HUNDLEY et al., 2013). Essa característica é específica para seu aproveitamento em biodigestores anaeróbios, visando concomitantemente à produção de biogás e biofertilizante, para serem reintroduzidos no sistema de aquaponia (FEROLDI et al., 2014). O estudo da produção de biogás em função do TRH pode ser analisado com o uso de modelos matemáticos, que levam em consideração a produção máxima de biogás, produção acumulada e tempo de partida (SANTOS et al., 2019; SILVEIRA et al., 2018; ANDRIAMANOHIARISOAMANANA et al., 2017; OPURUM et al., 2017; BUDIYONO et al., 2010; FLORENTINO et al., 2010; LOPES, 2007).

Dessa forma, objetivou-se avaliar a substituição da água no processo de digestão anaeróbica do dejeto bovino pelo lodo de piscicultura, por meio da caracterização quantitativamente a produção de biogás, modelagem matemática e equivalência energética do biogás gerado.

\section{MATERIAIS E MÉTODOS}

O experimento foi realizado no Laboratório de Eletrificação Rural e Energias Alternativas do Instituto de Tecnologia (IT)/Departamento de Engenharia (DE) da Universidade Federal Rural do Rio de Janeiro (UFRRJ), campus Seropédica - RJ, cujas coordenadas geográficas são 22 45' 33" S e 43 41' 51" W. O clima da região é classificado como Aw segundo a classificação de Köppen e temperatura média anual de $24,5^{\circ} \mathrm{C}$.

Os substratos utilizados nos processos de monodigestão anaeróbica (MoDA) e codigestão anaeróbica (CoDA) foram o lodo de piscicultura (LP) e dejeto de bovino (DB). O LP foi proveniente do sistema integrado de aquaponia entre piscicultura e hidroponia instalado no Grão Coworking em Irajá, Rio de Janeiro - RJ. O DB fresco foi coletado na Bovinocultura de Leite da UFRRJ, por meio de raspagem com pá de pedreiro, evitando-se materiais estranhos (solo, pasto e pedra). Na bovinocultura de leite da UFRRJ, adota-se sistema convencional de produção, em que os animais são alimentados com capim da Tanzânia (Panicum maximum), com milho, farelo de soja e farelo de trigo. Os substratos de LP e DB foram transferidos em bombonas de PVC, imediatamente após sua coleta, para o Laboratório de Eletrificação Rural e Energias Alternativas.

A caracterização físico-química do substrato (material de entrada) e digestato (material de saída) no biodigestor anaeróbico foi realizada quanto potencial hidrogeniônico $(\mathrm{pH})$, umidade $(U)$, teor de sólido total (ST), teor de sólido total fixo (STF) e teor de sólidos total volátil (STV), conforme recomenda a Legislação do CONAMA 375/06 para o uso agrícola de lodos de esgoto gerados em estações de tratamento de esgoto sanitário e seus produtos derivados. Para a determinação dos parâmetros em estudo, adotou-se a metodologia descrita pela APHA (2005). A biodegradabilidade (BD) foi determinada segundo a metodologia descrita por Andriamanohiarisoamanana et al. (2016).

\section{Sistema de aquaponia}

O sistema de aquaponia foi composto por criação de peixe do gênero Tilápia, alimentadas por ração comercial e produção de alface. A piscicultura em cultivo foi realizada em piscina com dimensões de $8,0 \mathrm{X}$ 
4,0 X 1,4 m e capacidade para 29.200 L de água. O sistema de hidroponia foi composto por seis sequências verticais de tubulações de policloreto de vinila (PVC) fixadas na parede. Cada tubulação possuía 26 orifícios individuais para a introdução das mudas de alface. $O$ tratamento da água da piscina para a recirculação para a piscicultura e hidroponia foi construído com quatro bombonas de PVC, sendo que parte da água que recirculava pela terceira bombona era destinada a hidroponia, enquanto a última retornava à piscina contendo os peixes. Essa última bombona foi destinada a filtragem biológica, composta por filtro de areia, mídias e perlon (composto por materiais de tecido e espumas) para reter alga, fezes de peixe e resto de ração. Esse material retido no sistema de filtragem foi denominado lodo de piscicultura (Figura 1).

a)

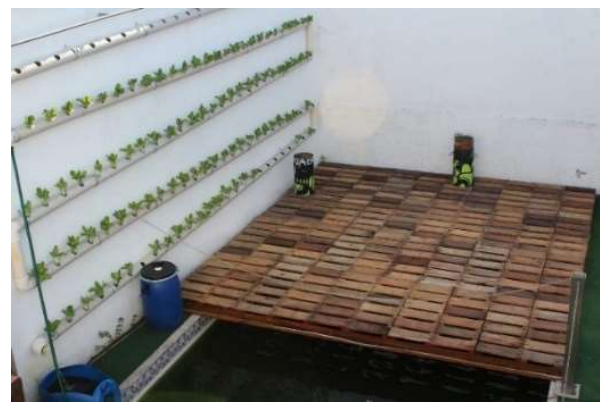

b)

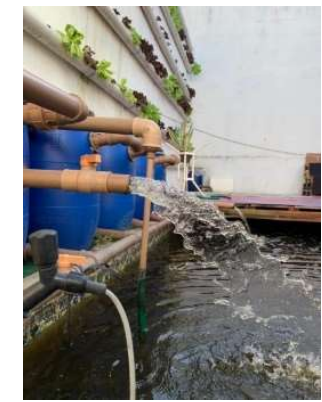

Figura 1: Sistema de aquaponia integrado com criação de peixe e cultura da alface: a) Hidroponia, b) Sistema de filtrações nas bombonas.

\section{Biodigestores anaeróbios de bancada modelo indiano}

O biodigestor anaeróbico utilizado no experimento foi baseado no modelo indiano, sendo constituído por câmara de contenção do "selo de água", câmara de digestão anaeróbica, manômetro de tubo em U (tendo água como líquido manométrico) e gasômetro, conforme no trabalho desenvolvido por Matos et al. (2017). No gasômetro fixou-se na parte lateral uma régua graduada em $\mathrm{cm} \mathrm{com}$ a finalidade de mensurar seu deslocamento vertical oriundo da produção de biogás. Na parte superior do gasômetro acoplou-se uma válvula de três vias visando a coleta dos dados de pressão e temperatura, teste de queima e descarga do biogás. No interior do gasômetro foi fixado uma mola de alumínio no gasômetro a fim de garantir que o substrato se mantivesse como mistura homogênea durante o processo de MoDA e CoDA. A medida em que o gasômetro se movimentava, devido à produção de biogás, a mola em formato espiral, homogeneizava o substrato no interior da câmara de digestão anaeróbica. Os gasômetros de cada biodigestor anaeróbico foram esvaziados totalmente após finalizada as mensurações de pressão, temperatura, deslocamento vertical do gasômetro e teste de queima.

Os biodigestores anaeróbios foram abastecidos com 1,7 kg de substrato nas relações de 100:0, 75:25, 50:50, 25:75, 0:100 LP:DB, com ensaios feitos em triplicata. 0 sistema de abastecimento ocorreu a batelada, ou seja, acondicionou-se o substrato no biodigestor anaeróbico apenas na entrada do experimento. No momento do abastecimento, considerou-se o tempo de retenção hidráulico (TRH) como zero. 0 abastecimento dos biodigestores anaeróbios com o substrato ocorreu até $12 \mathrm{~h}$ após sua coleta, a fim de evitar perda de biogás gerado devido ao precoce processo fermentativo. Finalizado o TRH, ou seja, período com produção de biogás nula, os biodigestores anaeróbios foram abertos. Assim, obteve-se o material de 
saída denominado como digestato.

\section{Monitoramento da temperatura do ambiente, biogás e substrato}

O monitoramento da temperatura ambiente (TA) e no interior do biodigestor anaeróbico (biogás e substrato), foi realizado com termopar conectado a milivoltímetro com precisão de $\pm 0,1{ }^{\circ} \mathrm{C}$. Para a mensuração da temperatura do biogás (TB), o termopar foi inserido na válvula de três vias. Já para a mensuração da temperatura do substrato (TS), o termopar fixo na campânula, manteve-se submerso na parte mediana da câmara de digestão anaeróbica.

\section{Análise do biogás}

O biogás gerado devido à digestão anaeróbica do lodo de piscicultura e dejetos de bovinos nos biodigestores anaeróbios foi analisado quanto a produção semanal (PS), produção acumulada (PA) e potencial de produção acumulada (PPA). As coletas de dados foram realizadas as segundas-feiras e quintasfeiras às 12:00 h. A PS de biogás foi obtida somando os dados obtidos durante uma semana (segunda-feira e quinta-feira). Para a PA de biogás, somou-se a PS anterior com a obtida na semana de coleta dos dados.

O volume de biogás produzido foi calculado por meio do produto do deslocamento vertical do gasômetro por sua área da seção transversal interna durante 16 semanas (114 dias) de digestão anaeróbica. A correção do volume de biogás para as condições de 1 atm $(101,32 \mathrm{kPa})$ e $20^{\circ} \mathrm{C}$ foi efetuada com base no trabalho realizado por Matos et al. (2017), no qual, pelo fator de compressibilidade, o biogás apresenta comportamento próximo ao ideal. Para a correção do volume de biogás, utilizou-se a expressão resultante da combinação das leis de Boyle e Gay-Lussac (Equação 1).

$$
\frac{V_{0} \times P_{0}}{T_{0}}=\frac{V_{1} \times P_{1}}{T_{1}}
$$

Em que, Vo é o Volume de biogás corrigido (L), Po é a Pressão corrigida do biogás (101,32 kPa), To é a Temperatura corrigida do biogás (293,15 K), V1 é o Volume do gás no gasômetro (L), P1 é a Pressão do biogás no instante da leitura ( $\mathrm{kPa}$ ) e $\mathrm{T}_{1}$ é a Temperatura do biogás, em K, no instante da leitura.

$P_{1}$ foi obtido pela soma entre a pressão atmosférica de Seropédica e pressão aferida nos manômetros acoplado ao gasômetro do biodigestor anaeróbico. A pressão média conferida nos manômetros foi em mm de $\mathrm{H}_{2} \mathrm{O}$ e convertida para $\mathrm{kPa}$. A pressão atmosférica de Seropédica foi aferida nos dias de condução do experimento na base de dados meteorológicos do Instituto Nacional de Meteorologia do Instituto Nacional de Meteorologia (INMET). Essa instituição possui a estação meteorológica automática de Ecologia Agrícola, localizada no município de Seropédica, Rio de Janeiro, Brasil localizada a 2,73km da UFRRJ.

O teste de queima foi realizado no momento de esvaziamento do gasômetro, em que uma mangueira acoplada na válvula de três vias e com o auxílio do bico de Bunsen detectou-se a presença ou não do gás metano $\left(\mathrm{CH}_{4}\right)$ no biogás (COSTA et al., 2013). Considerou-se presença de $\mathrm{CH}_{4}$, se ao colocar o biogás em presença do fogo no bico de Bunsen mantivesse a chama continuamente acesa, confirmando a queima. 


\section{Modelagem da cinética de produção acumulada de biogás}

Os dados experimentais de PA de biogás foram ajustados aos modelos de regressão não lineares, conforme apresentados na Tabela 1, conforme adotado por Silveira et al. (2018). Os valores de PA de biogás foram apresentados em L por TRH em semanas ( semana $\left.^{-1}\right)$.

Tabela 1: Modelos matemáticos ajustados à cinética de produção acumulada de biogás.

\begin{tabular}{lcc}
\hline Modelo & Equação & \\
\hline Sigmoide de Boltzmann & $\mathrm{Y}_{\mathrm{i}}=\mathrm{AI}+\frac{(\mathrm{AS}-\mathrm{AI})}{1+\exp ^{\frac{\mathrm{PI}-\mathrm{x}}{\mathrm{INC}}}+\mathrm{u}_{\mathrm{i}}}$ \\
Gompertz & $\mathrm{Y}_{\mathrm{i}}=\mathrm{AS} \times \exp ^{-\exp ^{(-\mathrm{NC} \times(\mathrm{X}-\mathrm{PI}))}+\mathrm{u}_{\mathrm{i}}}$ & (2) \\
Logístico & $\mathrm{Y}_{\mathrm{i}}=\frac{\mathrm{AS}}{1+\exp ^{-\mathrm{INC} \times(\mathrm{X}-\mathrm{PI})}+\mathrm{u}_{\mathrm{i}}}$ \\
\hline
\end{tabular}

Em que, $Y_{i}$ é a Produção de biogás acumulado na semana i $\left(\mathrm{L} \mathrm{kg}^{-1}\right)$, Al é a Assíntota Inferior (volume do biogás no momento da instalação), AS é a Assíntota Superior (volume total de biogás acumulado pelo sistema no final do TRH), INC é a Inclinação da curva no PI (máxima liberação de biogás), PI é o Ponto de Inflexão (momento no qual ocorre a máxima liberação de biogás), x é a Variável semana, i é a 1, ..., n, n é o Número de medições do biogás acumulado, exp é 2,71828 e uié o resíduo do ajuste na i-ésima medição.

O PPA de biogás foi calculado utilizando o parâmetro estatístico AS, obtido dos modelos de cinética da PA e a quantidade de substrato adicionado nos biodigestores anaeróbios $(1,7 \mathrm{~kg})$. Os valores foram expressos em $L$ de biogás por $k g$ de substrato $\left(\mathrm{L} \mathrm{kg}_{\text {substrato }}{ }^{-1}\right)$.

\section{Equivalência energética}

O cálculo da equivalência energética foi baseado no maior PPA de biogás dentre as relações LP:DB e para a MoDA, quantidade média de dejetos (QD) produzidos por bovinos em uma propriedade rural de pequeno porte e equivalência de um metro cúbico de gás com óleo diesel, lenha, gás de cozinha (GLP) e eletricidade. Para quantidade de dejetos, foi adotado 200 bovinos leiteiros, com produção de $15 \mathrm{~kg}$ de dejetos (animal dia ${ }^{-1}$ ) (BARREIRA, 2011). Sabendo-se o potencial de produção acumulada de biogás e a quantidade média de dejetos produzidos, foi determinada a produção de biogás (PB) gerado pela Equação 5 .

$$
P B=P P A \times Q D
$$

Em que, PB em m³ $\mathrm{m}^{3}$ PPA em $\mathrm{m}^{3} \mathrm{~kg}^{-1}$ e QD em $\mathrm{kg}$. A equivalência energética do biogás, em relação a outros combustíveis, foi determinada levando em conta o poder calorífico e a eficiência média de combustão. Apresenta-se na Tabela 2 a equivalência de biogás para cada combustível, segundo as fontes consultadas.

Tabela 2: Comparação entre o biogás e fontes energéticas.

\begin{tabular}{llll}
\hline Combustíveis fósseis & Equivalência de um $\mathrm{m}^{3}$ de biogás (EQB) & Unidade & Fonte \\
\hline Óleo diesel & 0,55 & $\mathrm{~L}$ & Nogueira (1986) \\
GLP & 1,43 & $\mathrm{~L}$ & Nogueira (1986) \\
Lenha & 1,54 & $\mathrm{Kg}$ & Barreira (2011) \\
Eletricidade & 1,43 & $\mathrm{KWh}$ & Barreira (2011) \\
\hline
\end{tabular}

Sabendo-se a equivalência de biogás para cada combustível, foi estimada a conversão energética (CE) 
para cada combustível conforme Equação 6.

$$
C E=P B \times E Q B
$$

Para o cálculo da economia energética do Óleo Diesel, GLP e Lenha foram considerados os relatórios de síntese dos preços praticados, tendo como base o valor médio repassado ao consumidor, do site da Agência Nacional do Petróleo (ANP) em 2020. Para a eletricidade, foi considerada a tarifa atual disponibilizada no site da Light SA (empresa de utilidade pública privada do Rio de Janeiro, Brasil) em 2020, para propriedades rurais localizadas no Rio de Janeiro com consumo de 51 a $300 \mathrm{kWh}$. De acordo com a referida concessionária, o valor vigente para a energia elétrica foi de $\mathrm{R} \$ \mathrm{kWh}^{-1} 0,737$, ou de US\$ $\mathrm{kWh}^{-1} 0.13$. Os valores monetários foram convertidos em dólares americanos (US\$), coletado em outubro de 2020, onde US\$ 1.00 equivale a R\$ 5,5393, segundo o Banco Central do Brasil (BCB) em 2020.

\section{Análise estatística}

Para a avaliação dos resultados referentes ao ensaio de MoDA e CoDA no sistema a batelada foi adotado delineamento inteiramente casualizado. O sistema a batelada foi composto de cinco relações (100:0, 75:25, 50:50, 25:75, 0:100 LP:DB), com três repetições (biodigestores anaeróbios).

A análise estatística das características físico-químicas do substrato e digestato foram submetidos à análise de variância, seguido do teste de Tukey ao nível de 5\% de probabilidade, pelo programa estatístico SISVAR. Os resultados experimentais da produção acumulada de biogás em função do tempo de retenção hidráulica foram ajustados aos modelos matemáticos. A seleção do modelo mais adequado, para explicar a produção acumulada de biogás nas semanas do estudo, foi feita com base na precisão dos ajustes, e obedeceu ao critério mais utilizado na área para comparar modelos com diferentes números de parâmetros coeficiente de determinação $\left(R^{2}\right)$, o melhor modelo será o que apresenta o maior valor para o $R^{2}$ (SILVEIRA et al., 2018; FERNANDES et al., 2014; PRADO et al., 2013). Para o ajuste dos modelos matemáticos, citados na Tabela 1 também se utilizou a variável do erro médio relativo $(\mathrm{P})$, considerando modelos satisfatoriamente ajustados aos que apresentarem valores de $\mathrm{P}$ abaixo de $10 \%$.

\section{RESULTADOS E DISCUSSÃO}

Apresenta-se na Tabela 3, os valores médios de potencial hidrogeniônico $(\mathrm{pH})$, umidade $(\mathrm{U})$, sólido total (ST), sólido total fixo (STF) e sólido total em base massa fresca (STV $\mathrm{BMF}_{\text {) }}$ nos substratos lodo de piscicultura e dejeto bovino.

Tabela 3: Valores médios de potencial hidrogeniônico $(\mathrm{pH})$, umidade (U), sólido total (ST), sólido total volátil em base

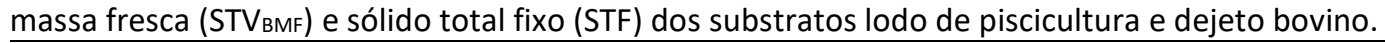

\begin{tabular}{lllll}
\hline Parâmetros & Lodo de Piscicultura & Dejeto Bovino & CV (\%) & Valor $\mathrm{p}$ \\
\hline $\mathrm{pH}$ & $6,16 \mathrm{~B}$ & $8,22 \mathrm{~A}$ & 2,31 & 0,0000 \\
$\mathrm{U}(\%)$ & $97,54 \mathrm{~A}$ & $78,95 \mathrm{~B}$ & 1,01 & 0,0000 \\
ST $(\%)$ & $2,46 \mathrm{~B}$ & $21,05 \mathrm{~A}$ & 7,72 & 0,0000 \\
STV & $81,41 \mathrm{~A}$ & $74,51 \mathrm{~A}$ & 5,85 & 0,1182 \\
STF (\%) & $0,44 \mathrm{~B}$ & $5,38 \mathrm{~A}$ & 13,59 & 0,0000 \\
\hline
\end{tabular}

Médias seguidas de letras maiúsculas distintas na mesma linha, diferem estatisticamente entre si na comparação entre os substratos Lodo de piscicultura: Dejeto Bovino (A; B) pelo teste de Tukey a $5 \%$ de probabilidade de erro. 
Os valores médios de pH para o substrato de LP e DB mostrados na Tabela 3 apresentaram intervalo ideal para a ocorrência do processo de DA com uma variação de 6,0 a 8,3, conforme relatado por Lourenço et al. (2019), Santos et al. (2019) e Andrade et al. (2016). É possível observar na Tabela 3 que os valores de pH do LP e DB encontraram-se dentro do limite da condição ideal apontada na literatura, garantindo o desenvolvimento da grande maioria das bactérias metanogênicas (JORDAN et al., 2020; LOURENÇO et al., 2019; OPURUM et al., 2017; NNABUCHI et al., 2012). Andriamanohiarisoamanana et al. (2016) consideraram o pH de 7,28 e Santos et al. (2019) valores entre 6,96 e 7,45 de dejeto bovino leiteiro ótimo para a atividade metanogênica. Segundo Opurum et al. (2017), ao estudarem DA com dejeto de peixe, encontraram valor de pH de 6,24 e observaram a associação do pH a produção de biogás, em que, ao elevar o valor do pH promovia o aumento na produção de biogás. Baumgartner et al. (2007) encontraram valor de pH de 6,35 no reuso de águas residuais da piscicultura, no sistema de aquaponia com a cultura da alface. Este valor é referente ao efluente do viveiro de cultivo semi-intensivo de Tilápia, alimentada com ração.

Nos valores médios referentes a $U$ foi constatado diferença estatística $(P>0,05)$, entre os substratos, após 16 semanas de TRH. O LP, por ser um material com sua composição majoritariamente de água do cultivo de Tilápia, apresentou valor de U de 97,54\%. Em estudos com DB fresco Andriamanohiarisoamanana et al. (2016) e Andrade et al. (2020) apresentaram valor médio umidade de 93,7 e 85\%, respectivamente. O uso de DB fresco elimina custo e tempo necessário para estabilização do substrato a ser usado em processos de digestão anaeróbica. Ainda, facilita a utilização imediata do dejeto bovino fresco oriundo das propriedades rurais e pequenas comunidades remotas, evitando a perda de umidade no trajeto do substrato ao biodigestor anaeróbico (ANDRADE et al., 2020).

A determinação dos sólidos é uma forma eficaz de mensurar a quantidade de nutriente disponível para ação bacteriana durante a DA do substrato, o qual representa a fração orgânica que pode ser convertida em biogás (SANTOS et al., 2019; NNABUCHI et al., 2012). Conforme esperado, os valores médios de ST e STF do LP e DB apresentaram diferença estatística ao nível de 5\% de probabilidade (Tabela 3). No entanto, os valores relacionados ao STV em base de matéria seca $\left(\%-p p^{-1}\right)$ não obteve-se diferenças estatísticas entre si $(p>0,05)$, sendo de $2,5 \%$ de ST, $81,4 \%$ eram voláteis para LP e de $21,0 \%$ de ST, $74,5 \%$ voláteis para DB (Tabela 3).

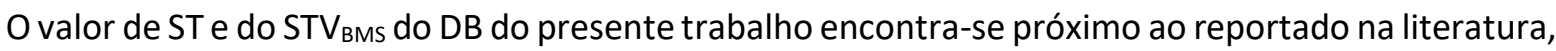
sendo, respectivamente de, 19,4 e 79,5\% (ANDRADE et al., 2016) e 19,2 e 80,9\% (ORRICO et al., 2016). No que tange ao LP, Opurum et al. (2017) ao trabalhar com DA entre dejeto de peixes e farinha de sangue bovino relataram valor de $4,0 \%$ de ST no efluente do viveiro de criação de peixes. Os sólidos totais fixos (STF) presentes nas amostras são a fração inorgânica do material, isto é, a parcela que não degrada pelo processo de digestão. O LP, por ter característica aquosa, apresenta menor valor, sendo de 0,44\%, em comparação ao dejeto bovino, de 5,38\%. Os autores Opurum et al. (2017) encontraram valores de 1,01\% para dejeto de peixes.

A redução do constituinte sólido está diretamente associada às produções de biogás, devido a degradação do material orgânico pelos microrganismos anaeróbios (ORRICO et al., 2016). No presente 


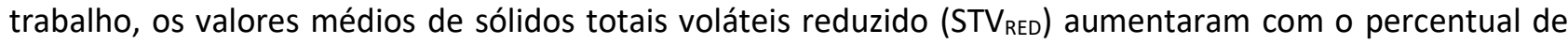
dejeto bovino. Para as relações $75: 25,50: 50,25: 75$ LP:DB o STV RED foi de $13,3 \%, 23,9 \%$ e $24,5 \%$, respectivamente.

Verificou-se elevada biodegradabilidade do LP com taxa STV/ST de 0,82. Comparando com LP, o DB apresentou menor valor de biodegradabilidade com taxa de 0,75. Em estudo realizado por Andriamanohiarisoamanana et al. (2016) relataram que a taxa STV/ST do glicerol bruto $(0,91)$ superior ao dejeto bovino $(0,78)$ favoreceu a CoDA entre esses substratos devido ao fato de aumentar a disponibilidade de nutrientes para atividade microbiana do glicerol bruto e a biodegradabilidade de matéria orgânica no biodigestor anaeróbio em aproximadamente duas vezes.

\section{Perfil da temperatura do ambiente, substrato e biogás}

A temperatura é um dos fatores que pode influenciar significativamente a atividade microbiana e, portanto, o desempenho da DA. Na Figura 2, nota-se que TA, TS e TB média seguiram a mesma tendência de comportamento ao longo do TRH de 16 semanas, variando no máximo $4{ }^{\circ} \mathrm{C}$ entre as mesmas. Segundo Tavares et al. (2016) as variações de temperaturas internas no biodigestor anaeróbico (TS e TB) ocorrem principalmente devido às variações das temperaturas externas, e por consequência relaciona-se com a produção de biogás. A TS manteve-se dentro da faixa de temperatura mesofilica, independente da relação estudada, variando entre 23,6 e $30,2^{\circ} \mathrm{C}$ (Figura 2). Na faixa mesofílica, o processo de DA ocorre com maior estabilidade e requer menores custos com energia para manter o substrato na temperatura ideal.

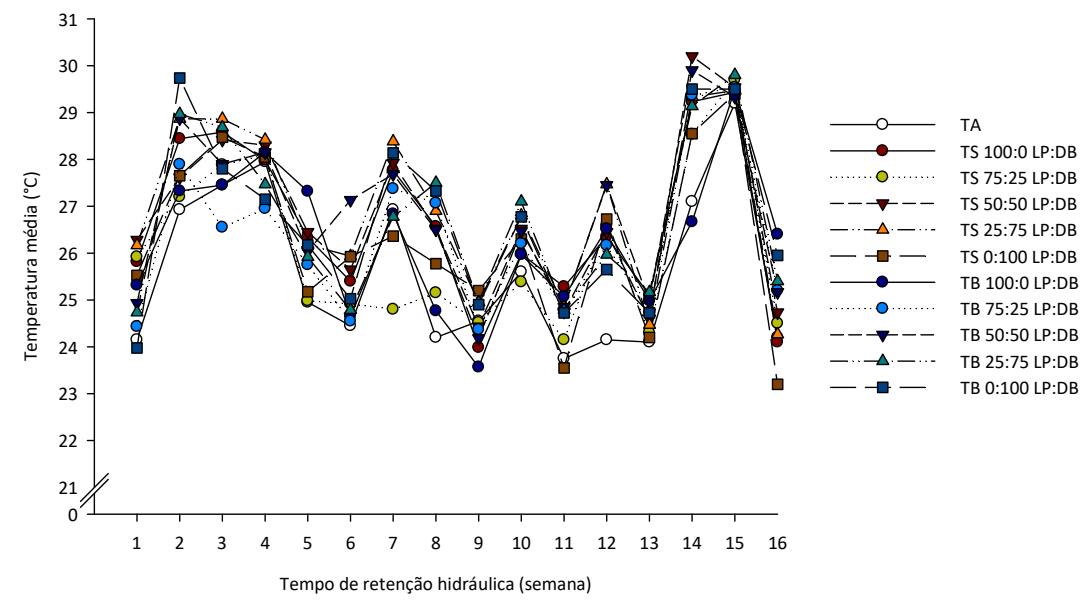

Figura 2: Perfil de temperatura ambiente (TA), temperatura do substrato (TS), e temperatura do biogás (TB) em função do tempo de retenção hidráulica (semana).

\section{Perfil de produção de biogás}

Verificou-se imediata produção de gás para todas as relações LP:DB, com exceção da MoDA do LP (Figura 3). No entanto, ao realizar o teste de queima, a produção de biogás iniciou apenas a partir da terceira semana, com a chama se mantendo acessa. Este comportamento pode estar atrelado a etapa inicial do processo de DA, em que ocorre a ação de bactérias aeróbicas e facultativas com a função de consumir o oxigênio existente no meio sem a produção de biogás (ОTOBONI et al., 2017; DOTTO et al., 2012). 


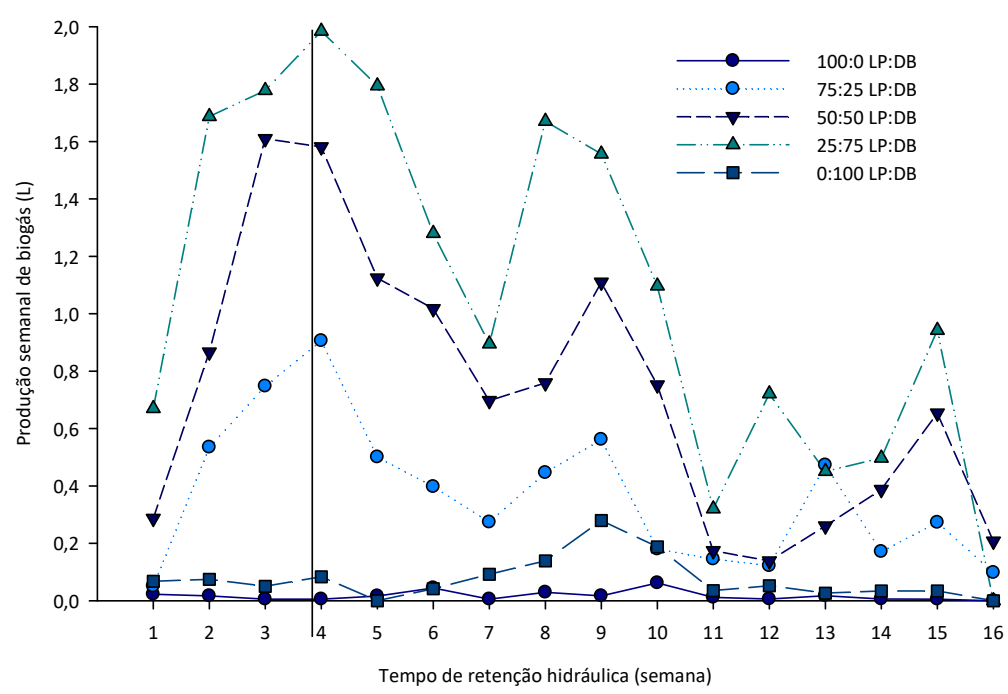

Figura 3: Produção semanal de biogás (L) em função do tempo de retenção hidráulica (semana).

No processo de CoDA o pico principal de produção de biogás ocorreu na quarta semana, sendo em ordem decrescente de 1,984, 1,610 e 0,906 L para 25:75, 50:50 e 75:25 LP:DB, respectivamente. Ao longo do TRH, a produção de biogás se manteve, com segundo pico na oitava semana para 25:75 LP:DB e na nona semana para 50:50 e 75:25 LP:DB, seguido de queda de produção (Figura 3).

No que tange à MoDA, o LP não produziu biogás ao longo do TRH, enquanto o DB apresentou pico principal de produção de biogás de 0,279 L na nona semana de experimento (Figura 3). O longo período apresentado para o substrato contendo apenas DB pode estar relacionado à dificuldade da carga microbiana em degradar a matéria orgânica, devido à falta de água (PAGANI et al., 2019).

No trabalho realizado por Pagani et al. (2019), ao avaliarem a adição de água em dejetos bovinos (A:DB) como estratégia de otimização do processo de digestão anaeróbica, obtiveram o pico de produção de biogás de 3,3 e 1,5 L na sétima semana, para as proporções de 25:75 e 50:50 A:DB, respectivamente. Com base no trabalho realizado por esses autores, é possível afirmar que o LP pode ser um codigestante que antecipa o pico de produção. Ainda, pode-se afirmar que no processo de CoDA com DB, LP elimina a necessidade de se utilizar água, como geralmente é adotado na DA (PAGANI et al., 2019; SANTOS et al., 2019; MATOS et al., 2017), embora esse substrato não tenha produzido biogás ao longo do TRH (Figura 3).

\section{Modelagem matemática de produção acumulada de biogás}

Os modelos matemáticos ajustados aos dados experimentais apresentaram coeficiente de determinação superior à 98\%, exceto o modelo Logístico para a relação de 75:25 LP:DB (Tabela 4). Elevado valor de coeficiente de determinação indica representação satisfatória do fenômeno em estudo, tal como, a predição da cinética de PA em função do TRH (OTARAKU et al., 2020; REGOA et al., 2019).

Dentre os modelos analisados, o Sigmoide de Boltzmann (Equação 2) para as relações 75:25 e 0:100 LP:DB e o Gompertz (Equação 3) para 50:50 e 25:75 LP:DB, foram considerados os melhores para estimar as curvas de cinética de produção acumulada de biogás, apresentando valores maiores de $\mathrm{R}^{2}$, inferiores a $10 \%$ 
de P e menores de SE e DQM (Tabela 4).

Tabela 4: Coeficiente de determinação $\left(R^{2}\right)$, erro médio relativo $(P)$, desvio padrão da estimativa (SE) e desvio quadrático médio (DQM) para ajuste dos modelos de cinética de produção acumulada de biogás nas relações 75:25, 50:50, 25:75, 0:100 LP:DB.

\begin{tabular}{|c|c|c|c|c|c|}
\hline $\begin{array}{l}\text { Relação } \\
\text { LP:DB }\end{array}$ & Modelo & $\mathrm{R}^{2}(\%)$ & $\mathrm{P}(\%)$ & SE (decimal) & DQM (decimal) \\
\hline & Sigmoide de Boltzmann & 98,86 & 2,99 & 0,19 & 0,17 \\
\hline \multirow[t]{3}{*}{$75: 25$} & Gompertz & 98,66 & 4,44 & 0,21 & 0,18 \\
\hline & Logístico & 97,50 & 5,42 & 0,29 & 0,25 \\
\hline & Sigmoide de Boltzmann & 98,98 & 3,01 & 0,36 & 0,31 \\
\hline \multirow[t]{3}{*}{$50: 50$} & Gompertz & 99,06 & 3,91 & 0,35 & 0,30 \\
\hline & Logístico & 98,12 & 4,61 & 0,49 & 0,43 \\
\hline & Sigmoide de Boltzmann & 99,34 & 2,92 & 0,45 & 0,39 \\
\hline \multirow[t]{3}{*}{$25: 75$} & Gompertz & 99,41 & 3,37 & 0,42 & 0,37 \\
\hline & Logístico & 98,63 & 3,65 & 0,64 & 0,56 \\
\hline & Sigmoide de Boltzmann & 99,54 & 8,36 & 0,03 & 0,03 \\
\hline \multirow[t]{2}{*}{$0: 100$} & Gompertz & 99,08 & 16,38 & 0,05 & 0,04 \\
\hline & Logístico & 99,50 & 9,81 & 0,03 & 0,03 \\
\hline
\end{tabular}

$\mathrm{Na}$ Figura 4, apresentam-se os valores observados e os preditos pelos modelos sigmoides, com seus coeficientes em função das relações LP:DB estudadas, para a descrição da PA de biogás ao longo do TRH. Verificou-se correspondência satisfatória dos modelos sigmoides ajustados aos valores observados, os quais se encontram próximos à reta que passa pela origem, que teoricamente representa a igualdade entre os valores. Observou-se ajuste adequado do modelo aos dados experimentais da produção acumulada de biogás, com valores observados próximos aos valores preditos pelo modelo.

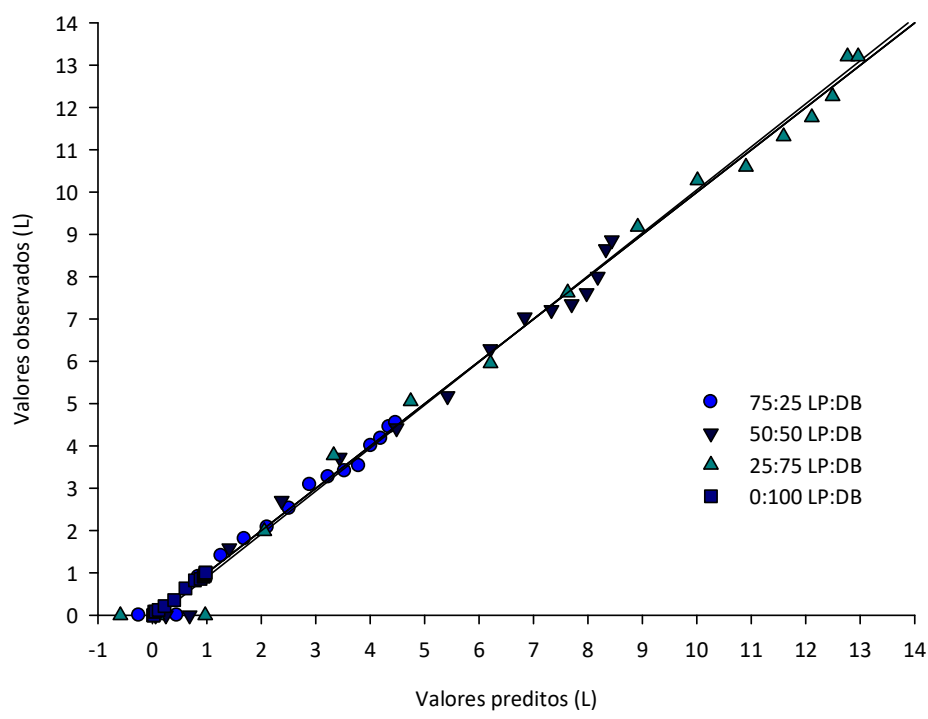

Figura 4: Relação entre os valores experimentais e estimados da produção acumulada de biogás pelos modelos Sigmoide de Boltzmann para 75:25 e 0:100 LP:DB e Gompertz para 50:50 e 25:75 LP:DB.

Apresenta-se na Tabela 5 os parâmetros estatísticos Al, AS, INC e PI oriundo dos modelos selecionando no critério de seleção Sigmoide de Boltzmann e Gompertz para estimar as curvas de cinética de PA de biogás em função do TRH. 
Tabela 5: Parâmetros estatísticos de assíntota inferior (AI), assíntota superior (AS), inclinação da curta no ponto PI (INC) e ponto de inflexão (PI) obtido dos modelos de cinética ajustado às curvas de cinética de produção acumulada de biogás para as relações 75:25, 50:50, 25:75 e 0:100 LP:DB.

\begin{tabular}{lllll}
\hline Relação LP:DB & Modelo & Al & AS & INC \\
\hline $75: 25$ & Sigmoide de Boltzmann & $-1,89 \pm 1,25$ & $4,95 \pm 0,43$ & $4,01 \pm 1,12$ \\
$50: 50$ & Gompertz & - & $8,72 \pm 0,27$ & $0,34 \pm 0,03$ \\
$25: 75$ & Gompertz & - & $13,55 \pm 0,37$ & $0,32 \pm 0,02$ \\
$0: 100$ & Sigmoide de Boltzmann & $0,02 \pm 0,02$ & $0,98 \pm 0,02$ & $1,14 \pm 0,10$ \\
\hline
\end{tabular}

Os valores de Al estimados pelo modelo Sigmoide de Boltzmann (Equação 2) confirmam que não houve produção de biogás no momento da instalação (Tabela 5). De acordo com Silveira et al. (2018), dentre os modelos analisados para estudar a cinética de PA, somente o Sigmoide de Boltzmann apresenta parâmetro para modelar o início da curva de acúmulo de biogás e Al representa menor interesse prático.

O parâmetro AS estimado pelo modelo Gompertz (Equação 3) apresentou valor superior para 25:75 LP:DB, quando comparado com as demais relações. Confirmando o apresentado na Figura 5, infere-se que quanto maior a proporção de $\mathrm{DB}$, maior o volume total de biogás acumulado pelo sistema ao longo de 16 semanas, sendo em ordem decrescente de 13,55; 8,72; 4,95; 0,98 L para 25:75; 50:50; 75:25 e 0:100 LP:DB, respectivamente, para cada modelo selecionado (Tabela 5). Segundo Silveira et al. (2018), o parâmetro AS pode ser considerado um dos valores de maior importância na cinética de PA de biogás. Os autores destacam a importância desse parâmetro, visto que por meio do conhecimento do volume máximo de biogás acumulado ao longo do tempo máximo de funcionamento é possível ter precisão no dimensionamento dos biodigestores anaeróbios e estimar a quantidade e o custo para a produção de energia a ser produzida pelo sistema.

O parâmetro INC refere-se ao aumento da velocidade de acúmulo de biogás no ponto de inflexão (SILVEIRA et al., 2018). De acordo com a Tabela 5, verificou-se que o menor INC foi estimado pelo modelo Gompertz para a relação 25:75 LP:DB, a qual apresentou maior PA. No modelo sigmoide de Boltzmann este parâmetro foi superior ao estimado no modelo Gompertz, sendo cerca de três vezes maior para 0:100 LP:DB e 11 vezes maior para 75:25 LP:DB. No trabalho desenvolvido por Silveira et al. (2018), o modelo Sigmoide de Boltzmann estimou maiores valores de INC.

O parâmetro PI indica o momento onde ocorre 50 e 37\% do total da produção de biogás nos modelos Sigmoide de Boltzmann e Gompertz, respectivamente (SILVEIRA et al., 2018). Para a CoDA o PI foi estimado próximo da sexta semana independente do modelo, ao passo que na MoDA com nove semanas (Tabela 5). Desta forma, fica evidente a necessidade CoDA entre DB e LP, a fim de otimizar a DA.

Apresenta-se na Figura 5 as curvas dos ajustes dos valores experimentais pelos modelos Sigmoide de Boltzmann e Gompertz para produção acumulada de biogás nas relações de 75:25, 50:50, 25:75 e 100:0 LP:DB. A curva de produção acumulada de biogás apresentou caráter sigmoidal, independente da relação utilizada, conforme reportado por Florentino et al. (2010) e Silveira et al. (2018) para CoAD e atividade metanogência especifica, respectivamente, com modelo Sigmoide de Boltzmann, e Lopes (2007) com modelo Gompertz. Santos et al. (2019), Andriamanohiarisoamanana et al. (2017), Opurum et al. (2017) e Budiyono et al. (2010) obtiveram melhores ajustes dos dados experimentais de produção acumulada de biogás com o modelo Gompertz modificado. 


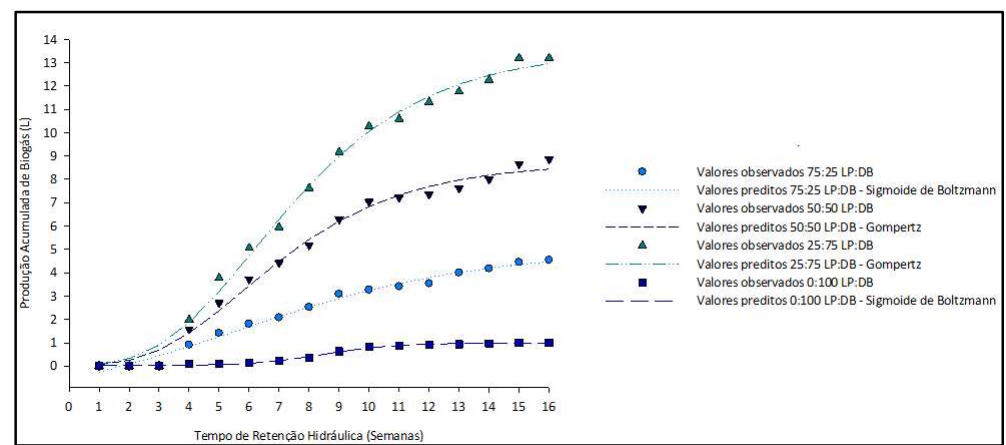

Figura 5: Cinética de produção acumulada de biogás (L) em função do tempo de retenção hidráulica (semana) utilizando os modelos Sigmoide de Boltzmann e Gompertz para o ajuste dos dados observados.

Como esperado, pode-se observar na MoDA ausência de produção acumulada de biogás ao se utilizar apenas LP. Já para MoDA de apenas DB, observou-se início de produção acumulada de biogás tardia, bem como geração inferior ao apresentado na CoDA (Figura 5).

Verificou-se, na codigestão anaeróbica, aumento na PA de biogás ao aumentar o percentual de DB. Esse comportamento já era esperado, uma vez que, com o aumento da carga de matéria orgânica cria-se melhor condição para o desenvolvimento de bactérias anaeróbicas (metanogênicas) e, consequentemente, produção de biogás (PEREIRA et al., 2015). Pagani et al. (2019) e Santos et al. (2019) relataram que biodigestores anaeróbios com maior carga orgânica de dejeto bovino apresenta maior produção e taxa de produção de $\mathrm{CH}_{4}$ comparado a biodigestores anaeróbios com maiores diluições em água.

Ainda, independentemente da relação utilizada na CoAD adotada, a produção acumulada de biogás iniciou na quarta semana. Andrade et al. (2016) relataram início da produção de biogás tardia no presente trabalho, onde avaliaram a produção de biogás em biodigestores anaeróbios semicontínuos alimentados com dejetos de ruminantes e monogástricos codigeridos com manipueira. Os autores verificaram produção diária de biogás inferior a $1 \mathrm{~L}$ até a quinta semana, e após esta, alcançaram valores em média de 3,5 L em TRH de 18 semanas.

Essas diferenças nos tempos de produção de biogás podem estar relacionadas com as características físicas e químicas dos substratos, nas quais variam em função dos valores de pH, temperatura do substrato, tipo de biodigestor anaeróbico, e também com a umidade inicial.

\section{Potencial de produção acumulada de biogás}

Os valores de PPA obtidos foram de 2,91; 5,13; 7,97 e 0,58 $\mathrm{L} \mathrm{kg}^{-1}$ substrato para as relações de 75:25; 50:50; 25:75; 0:100 LP:DB, respectivamente, na 16 semana de DA. Os PPA para a CoDA neste estudo apresentaram valores semelhantes aos valores reportados por Pagani et al. (2019). No entanto, no trabalho realizado por esses autores, o DB foi diluído em água. Esses resultados evidenciam o efeito positivo da CoDA com LP, uma vez que, possui carga orgânica superior a água, favorecendo a produção de biogás.

Ressalta-se a importância em escolher a relação ideal da mistura para favorecer o sinergismo, diluir compostos inibitórios e tóxicos, aperfeiçoar a produção de biogás e $\mathrm{CH}_{4}$ e promover a qualidade do produto e a estabilidade da digestão anaeróbica (PANIGRAHI et al., 2019; ANDRIAMANOHIARISOAMANANA et al., 2017; ANDRIAMANOHIARISOAMANANA et al., 2018; MATA-ALVAREZ et al., 2014). Observou-se na CoDA, que 
quanto menor a diluição do DB em LP, maiores foram os valores de PPA. Provavelmente, dejetos bovino menos diluído em lodo de piscicultura, torna o ambiente anaeróbico mais propício para a proliferação e atividade das bactérias metanogênicas, acarretando em maior geração de biogás. Segundo Pagani et al. (2019) e Santos et al. (2019), o fator de diluição influencia no potencial de produção de biogás e $\mathrm{CH}_{4}$, respectivamente. Segundo Santos et al. (2019), o dejeto bovino diluído em água com fator de diluição de 1:2 apresentou maior concentração de $\mathrm{CH}_{4}$ no biogás (80\%), com tempo relativamente baixo para início da produção desse componente quando comparado com 1:6 e 1:10.

Em adição, verificou-se que a grande maioria dos trabalhos publicados em periódicos nacional e internacional adotam a diluição do substrato dejeto bovino em água (PAGANI et al., 2019; SANTOS et al., 2019; SOARES et al., 2019; DOTTO et al., 2012; WEBER et al., 2014) e a relação de 1:1 A:DB (MATOS et al., 2017; PAES et al., 2020). Diante desses fatores, pode-se inferir que o lodo de piscicultura pode ser um potencial substituinte à utilização de água em sistema de DA, podendo ser usado em menor quantidade devido a sua superior carga orgânica. Todavia, reafirma-se que a CoDA tem resultados satisfatórios com a utilização de menores proporções do lodo de piscicultura, oferecendo destinação adequada sobre o resíduo agrícola e preservação no uso da água. O uso do lodo de piscicultura ao invés da água potável para a diluição do substrato possui o benefício de conter uma carga de microrganismo maior, sendo um inóculo de grande potencial. A reutilização do lodo de piscicultura pode ser considerada como procedimento para contribuir com o conceito de economia circular.

\section{Equivalência energética}

A partir do maior valor do PPA de biogás na CoDA, determinou-se a equivalência energética mensal, pressupondo o abastecimento dos biodigestores anaeróbios com a quantidade de $750 \mathrm{~kg} \mathrm{dia}^{-1} \mathrm{de} \mathrm{LP}$, para $3000 \mathrm{~kg} \mathrm{dia}^{-1}$ de DB, utilizando-se um potencial de $29,9 \mathrm{~m}^{3} \mathrm{dia}^{-1}$. Adicionalmente, verificou-se a avaliação para a MoDA na relação 0:100 LP:DB.

Apresenta-se na Tabela 6, a equivalência energética dos combustíveis fósseis gerada para as relações entre o LP e DB, onde ocorreu aumento de $94,2 \%$ para todos os combustíveis ao adotar a CoDA.

Tabela 6: Equivalência energética dos combustíveis fósseis mensal para as relações 25:75 e 0:100 LP:DB.

\begin{tabular}{lll}
\hline Combustíveis fósseis & Equivalência 25:75 LP:DB & Equivalência 0:100 LP:DB \\
\hline Óleo diesel (L) & 495,9 & 28,7 \\
GLP (L) & 407,1 & 23,6 \\
Lenha $(\mathrm{kg})$ & 1377,3 & 79,7 \\
Eletricidade (kWh) & 1282,3 & 74,2 \\
\hline
\end{tabular}

O uso de biodigestores para geração de biogás consiste em uma tecnologia viável, que possibilita a geração de energia in loco, diminuindo a dependência energética aos combustíveis convencionais, reduzindo os custos e contribuindo com a economia circular. O biogás pode ser aplicado no aquecimento de fogões, combustível para motores de combustão interna, geração de energia elétrica, térmica e mecânica (SANTOS et al., 2019; PEREIRA et al., 2015). Portanto, além da diversificação da matriz energética, tem-se o desenvolvimento econômico com aumento do emprego e da renda (FERREIRA et al., 2018). 
De acordo com o Balanço Energético Nacional de 2020 ano base 2019 realizado pela Empresa de Pesquisa Energética, o setor agropecuário se baseia em três principais matrizes energéticas, a lenha, o óleo diesel e a eletricidade, nas quais totalizam cerca de $94,4 \%$ desta matriz. Ao longo dos anos, evidencia-se no relatório, o crescimento de outras fontes de geração de energia, tais como o biogás.

A utilização do biogás pode ser uma alternativa para suprir estas fontes em propriedades rurais, diminuindo custos com energia, além de ser ambientalmente viável. No consumo da população brasileira, a lenha é a maior responsável pela emissão de GEE (GIODA, 2018). Segundo Vale et al. (2003), ao substituir o uso da lenha pelo biogás, contribui-se na redução da liberação de gases tóxicos originados de combustão. Os autores consideram que o consumo residencial de lenha é equivalente a 10,54 kg a cada domicílio com cinco pessoas. A CoDA ao gerar 1377,3 kg (Tabela 6), viabiliza a substituição do consumo mensal de lenha para 133 domicílios, auxiliando a comunidade ao entorno com o não desmatamento local para obtenção deste combustível (VARGAS et al., 2019).

Assim como a lenha, o uso do GLP pode ser vastamente utilizado para a geração de energia térmica em preparo de alimentos e aquecimento de água. No Brasil, o seu uso chega a mais de $90 \%$, porém, o biogás tem um menor impacto ambiental (GIODA, 2018). No cálculo para a possível economia gerada para equivalência energética do GLP, obteve-se como parâmetro, a quantidade e o valor vigente para botijões, sendo este de 13 L e R\$ 63,76, segundo ANP em 2020 ou US\$11.51. Considerando o valor em dólares americanos (US\$), estima-se uma economia mensal de US\$ 355.04 para a relação 25:75 LP:DB, comparado a US\$ 20.86, utilizando-se nos biodigestores anaeróbios somente o dejeto bovino.

Atualmente, existe o Programa de Desenvolvimento de Geração Distribuída de Energia Elétrica (ProGD) no Brasil, na qual permite o repasse da energia elétrica gerado in loco para uma distribuidora de energia. Ao conduzir a produção de energia elétrica gerada no domínio da propriedade, tem-se o benefício de ganhos monetários acordados com a distribuidora. Com o uso do biogás, pode se obter uma diminuição no valor mensal de até US\$170.58 e de US\$ 9.87 para a relação 25:75 e 0:100 LP:DB, respectivamente.

Segundo Pereira et al. (2017), um grupo eletrogêneo com motor de combustão a diesel para gerar eletricidade, necessita de 0,26 L para gerar $1 \mathrm{kWh}$. Caso ocorra a adoção de biodigestores anaeróbios para geração de energia elétrica, iria gerar 1907 kWh. Em termos monetários, considerando o valor do óleo diesel para classe de consumo $\mathrm{R} \$ \mathrm{~L}^{-1} 3,36$, ou de US\$ L $\mathrm{L}^{-1} 0.61$, pode ter uma economia de cerca de US\$300.42.

\section{CONCLUSÕES}

Por fim, pode-se inferir sobre o resultado obtido por este trabalho que o lodo de piscicultura ao ser utilizado na produção de biogás proporcionou benefícios a CoDA. As relações LP:DB obteve um ajuste satisfatório dos dados observados na produção acumulada pelos modelos matemáticos Sigmoide de Boltzmann e Gompertz com um $R^{2}$ acima de $98 \%$ para ambos. Na relação 25:75 LP:DB, foi aferido o maior PPA de biogás, sendo de 7,97 $\mathrm{L} \mathrm{kg}^{-1}$ substrato com TRH de 16 semanas, com a produção iniciada a partir da quarta semana. Por conseguinte, para esta mesma relação, constatou-se o maior rendimento energético, com aumento de $94 \%$ em todas as fontes, quando comparado ao tratamento com apenas dejeto bovino. 
Desta forma, afirma-se que as relações com atuação do lodo de piscicultura, mostraram-se mais eficientes em todas as avalições referentes à produção de biogás deste estudo, em vista a MoDA. Além disso, o uso deste substratos em biodigestores anaeróbios ofereceram fins ambientalmente adequados, comparado ao descarte in natura. Por fim, deve-se ressaltar que a substituição do LP pela água potável acarreta em atividade sustentável e dentro do que se preconoza com a economia circular.

\section{REFERÊNCIAS}

APHA. American Public Health Association. Standard methods for the examination water and wastewater. 21 ed. Washington: APHA, 2005.

ANDRADE, W. R.; XAVIER, C. A. N.; COCA, F. O. C. G.; ARRUDA, L. D. O.; SANTOS, T. M. B.. Biogas production from ruminant and monogastric animal manure co-digested with manipueira. Archivos de Zootecnia, v.65, n.251, p.375-380, 2016.

ANDRADE, M. M. M.; ALENCAR, B. R. A.; LEITE, N. P.; FIRMO, A. L. B.; DUTRA, E. D.; SAMPAIO, E. V. D. S. B.; MENEZES, R. S. C.. Biogas production from co-digestion of different proportions of food waste and fresh bovine manure. Biomass Conversion and Biorefinery, p.1-8, 2020. DOI: https://doi.org/10.1007/s13399-020-00833-8

ANDRIAMANOHIARISOAMANANA, F. J.; YAMASHIRO, T.; IHARA, I.; IWASAKI, M.; NISHIDA, T.; UMETSU, K.. Farm-scale thermophilic co-digestion of dairy manure with a biodiesel byproduct in cold regions. Energy Conversion and Management, v.128, p.273-280, 2016. DOI: https://doi.org/10.1016/j.enconman.2016.09.084

ANDRIAMANOHIARISOAMANANA, F. J.; SAIKAWA, A.; TARUKAWA, K.; QI, G.; PAN, Z.; YAMASHIRO, T.; IWASAKI, M.; IHARA, I.; NISHIDA, T.; UMETSU, K.. Anaerobic codigestion of dairy manure, meat and bone meal, and crude glycerol under mesophilic conditions: synergistic effect and kinetic studies. Energy for Sustainable Development, v.40, p.11-18, 2017. DOI: https://doi.org/10.1016/j.esd.2017.05.008

ANDRIAMANOHIARISOAMANANA, F. J.; SAIKAWA, A.; KAN, T.; QI, G.; PAN, Z.; YAMASHIRO, T.; IWASAKI, M.; IHARA, I.; NISHIDA, T.; UMETSU, K.. Semi-continuous anaerobic codigestion of dairy manure, meat and bone meal and crude glycerol: Process performance and digestate valorization. Renewable Energy, v.128, p.1-8, 2018. Dol: https://doi.org/10.1016/j.renene.2018.05.056

EPE; MME. Empresa de Pesquisa Energética; Ministério do Meio Ambiente. Balanço Energético Nacional 2020: Ano base 2019. Rio de Janeiro: EPE, 2020.

BARREIRA, P.. Biodigestores: energia, fertilidade e saneamento para zona rural. 3 ed. São Paulo: Ícone, 2011.

BATITUCCI, T. O.; CORTINES, E.; ALMEIDA, F. S.; ALMEIDA, A. A.. Agricultura en ecosistemas urbanos: un paso para la sostenibilidad de las ciudades. Ambiente \& Sociedade, v.22, 2019. DOI: https://doi.org/10.1590/18094422asoc0277r3vu19|4ao

BAUMGARTNER, D.; SAMPAIO, S. C.; SILVA, T. R. D.; TEO, C.
R.; BOAS, M. A. V.. Reúso de águas residuárias da piscicultura e da suinocultura na irrigação da cultura da alface. Engenharia Agrícola, v.27, n.1, p.152-163, 2007. DOI: https://doi.org/10.1590/S0100-69162007000100009

BRASIL. Fome zero: uma história brasileira. Brasília: Ministério do Desenvolvimento Social e Combate à Fome, 2010.

BUDIYONO, I. N.; WIDIASA, S.; JOHARI, S.. A cinética da taxa de produção de biogás de estrume de gado em modo de lote. Jornal Internacional de Engenharia Química e Biológica, v.3, n.1, p.39-45, 2010.

BUSS, A. B.; MEURER, V. N.; AQUINI, E. N.; ALBERTON, J. V.; BARDINI, D. S.; FRECCIA, A.. Desenvolvimento da aquaponia como alternativa de produção de alimentos saudáveis em perímetro urbano. Seminário de Ensino, Pesquisa e Extensão, v.4, p.1127-1132, 2015.

COSTA, L. V. C.; MOGHRABI, J. A.; SAGULA A. L.; JUNIOR, J. L.. Tratamento anaeróbio da água residuária de frigorífico com uso de biodigestores: utilização de remediadores biológicos para produção de biogás. Revista Brasileira de Engenharia de Biossistemas, v.7, n.2, p.77-85, 2013. DOI: http://dx.doi.org/10.18011/bioeng2013v7n2p77-85

DOTTO, R. B.; WOLFF, D. B.. Biodigestão e produção de biogás utilizando dejetos bovinos. Disciplinarum Scientia Naturais e Tecnológicas, v.13, n.1, p.13-26, 2012. DOI: https://doi.org/10.37779/nt.v13i1.1291

FERNANDES, T. J.; PEREIRA, A. A.; MUNIZ, J. A.; SAVIAN, T. V.. Seleção de modelos não lineares para a descrição das curvas de crescimento do fruto do cafeeiro. Coffee Science, v.9, n.2, 2014.

FEROLDI, M.; URIO, M. B.; ARAÚJO; A. V.; CREMONEZ, P. A.. Geração de biogás a partir de efluentes de abatedouros. Journal of Agronomic Sciences, v.3, p.130-148, 2014.

FERREIRA, L. R. A.; OTTO, R. B.; SILVA, F. P.; SOUZA, S. N. M.; SOUZA, S. S.; ANDO, O. H. J.. Revisão do potencial energético da biomassa residual para a geração distribuída no Brasil. Revisões de Energia Renovável e Sustentável, v.94, p.440455, 2018. DOI: https://doi.org/10.1016/j.rser.2018.06.034

FLORENTINO, H. O.; BISCARO, A. F. V.; PASSOS, J. R. S.. Funções sigmoidais aplicadas na determinação da atividade metanogênica específica-AME. Revista Brasileira de Biometria, p.141-150, 2010.

FAO. Food and Agriculture Organization of the United Nations. Perspectivas agrícolas FAO/OECD 2019-2028. Roma: FAO, 2019. 
GIODA, A.. Comparação dos níveis de poluentes emitidos pelos diferentes combustíveis utilizados para cocção e sua influência no aquecimento global. Química Nova, v.41, n.8, p.839-848, 2018. DOI: http://dx.doi.org/10.21577/0100$\underline{4042.20170260}$

HUNDLEY, G. C.; NAVARRO, R. D.. Aquaponia: a integração entre piscicultura e a hidroponia. Revista Brasileira de Agropecuária Sustentável, v.3, p.52-61, 2013. DOI: https://doi.org/10.21206/rbas.v3i2.218

JORDAN, R. A.; MARTINS, V. P.; ALMEIDA, A. C. S.; OLIVEIRA, F. C.; QUEQUETO, W. D.; SIQUEIRA, V. C.; SANTOS, R. C.. Potencial de produção de biogás de resíduos provenientes da criação de tilápia em sistema aquapônico. Research, Society and Development, v.9, n.9, 2020. DOI: https://doi.org/10.33448/rsd-v9i9.7131

LOPES, G. N.. Modelagem não linear da produção acumulada de biogás em rede de biodigestores anaeróbios. Revista Agroambiente, v.1, n.1, p.37-40, 2007.

LOURENÇO, V. A.; NADALETI, W. C.; VIEIRA, B. M.; LEANDRO, D.; SILVA, M. A.; SANTOS, R. F.; SANTOS, G. B.; VALENTINI, M. H. K.; SCHOELER, G. P.; KOSCHIER, I. F.; DUARTE, V. H.; CORRÊA, A. G.. Produção de biogás via codigestão anaeróbia de efluente da parboilização de arroz e resíduos orgânicos. Revista Ibero-Americana de Ciências Ambientais, v.10, n.4, p.219-231, 2019. DOI: https://doi.org/10.6008/CBPC21796858.2019.004.0017

MARISCAL-LAGARDA, M. M.; PÁEZ-OSUNA, F.; ESQUERMÉNDEZ, J. L.; GUERRERO-MONROY, I.; DEL VIVAR, A. R.; FÉLIX-GASTELUM, R.. Integrated culture of white shrimp (Litopenaeus vannamei) and tomato (Lycopersicon esculentum Mill) with low salinity groundwater: management and production. Aquaculture, v.366, p.76-84, 2012. DOI:

https://doi.org/10.1016/j.aquaculture.2012.09.003

MATA-ALVAREZ, J.; DOSTA, J.; ROMERO-GÜIZA, M. S.; FONOLL, X.; PECES, M.; ASTALS, S. S.. A critical review on anaerobic co-digestion achievements between 2010 and 2013. Renewable and Sustainable Energy Reviews, v.36, p.412- 27, 2014. DOI:

https://doi.org/10.1016/j.rser.2014.04.039

MATOS, C. F.; PAES, J. L.; PINHEIRO, E. F. M.; CAMPOS, D. V. B.. Biogas production from dairy cattle manure, under organic and conventional production systems. Revista Engenharia Agrícola, v.37, p.1081-1090, 2017. DOI: http://dx.doi.org/10.1590/1809-4430eng.agric.v37n6p1081-1090/2017

NNABUCHI, M. N.; AKUBUKO, F. O.; AUGUSTINE, C.; UGWU G. Z.. Avaliação do efeito da co-digestão de dejetos de galinha e esterco de vaca na geração de biogás. Global Journal of Science Frontier Research, v.12, n.7-A, 2012.

NOGUEIRA, L. A. H.. Biodigestão e a alternativa energética. São Paulo: Nobel, 1986.

OPURUM, C. C.; NWEKE, C. O.; NWANYANWU, C. E.; ORJI, J. C.. Biogas production from fishpond effluent supplemented with cow blood meal in a batch anaerobic digester system. Futo Journal Series, v.3, n.1, p.166-175, 2017.
ORRICO, A. C.; LOPES, W. R.; MANARELLI, D. M.; ORRICO JUNIOR, M. A.; SUNADA, N. D. S.. Codigestão anaeróbia dos dejetos de bovinos leiteiros e óleo de descarte. Engenharia Agrícola, v.36, n.3, p.537-545, 2016. DOI:

http://dx.doi.org/10.1590/1809-4430-Eng.Agric.v36n3p537$\underline{545 / 2016}$

OTARAKU, I. J.; ANAELE, J. V.. Modelling the cumulative biogas produced from sawdust, cow dung and water hyacinth. International Journal of Advanced Engineering Research and Science, v.7, n.3, 2020. DOI: https://dx.doi.org/10.22161/ijaers.73.66

OTOBONI, A. M. M. B.; XAVIER, D. O.; GIANNON, J. A.; TRAVAGLIN, M.; NUNES, M. M.; JORGE, P. S.; PARDO, R. B.; MOREIRA, J. P.. Biodigestão anaeróbia: associação de dejetos animais e resíduos vegetais. Revista Unimar Ciências, v.25, n.1-2. 2017.

PAES, J. L.; SANTOS, P. T. D.; VALADÃO, R. C.; DAMM, S. E. G. A.; PAGANI, G. F.; VARGAS, B. C.. Geração de eletricidade renovável a partir do biogás da co-digestão anaeróbica de lodo, esterco de gado e água. Brazilian Journal of Development, v.6, n.5, p.23319-23334, 2020. DOI: https://doi.org/10.34117/bjdv6n5-038

PAGANI, G. F.; PAES, J. L.; SANTOS, P. T.; VALADÃO, R. C.; MERLO, M. A. O.; CUNHA, J. P.B.; VARGAS, B. C.. Adição de água em dejetos bovinos como estratégia de otimização do processo de biodigestão anaeróbica. In: Meio ambiente e desenvolvimento sustentável. Atena, 2019. p.23-33.

PANIGRAHI, S.; DUBEY, B. K.. A critical review on operating parameters and strategies to improve the biogas yield from anaerobic digestion of organic fraction of municipal solid waste. Renewable Energy, v.143, p.779-797, 2019. DOI: https://doi.org/10.1016/i.renene.2019.05.040

PEREIRA, V.; FERREIRA, J. M. J.; MARTINEZ, G. A. S.; TOMACHUK, C. R.. Avaliação de sistema de colunas para remediação de biogás a partir de biomassa não digerida. Holos, v.8, n.31, p.242-251, 2015. DOI: http://doi.org/10.15628/holos.2015.2688

PEREIRA, P. H. S.. Dimensionamento e avaliação do ciclo de vida (ACV) da produção de biodiesel por microalgas cultivadas em vinhaça em uma usina sucroalcooleira. Tese (Doutorado) - Escola de Engenharia de São Carlos da Universidade de São Paulo, São Paulo, 2017.

PRADO, T. K. L.; SAVIAN, T. V.; MUNIZ, J. A.. Ajuste dos modelos Gompertz e Logístico aos dados de crescimento de frutos de coqueiro anão verde. Ciência Rural, v.43, n.5, p.803-809, 2013. DOI: http://dx.doi.org/10.1590/S0103$\underline{84782013005000044}$

QI, G.; PAN, Z.; SUGAWA, Y.; ANDRIAMANOHIARISOAMANANA, F. J.; YAMASHIRO, T.; IWASAKI, M.; UMETSU, K.. Comparative fertilizer properties of digestates from mesophilic and thermophilic anaerobic digestion of dairy manure: focusing on plant growth promoting bacteria (PGPB) and environmental risk. Journal of Material Cycles and Waste Management, v.20, n.3, p.1448-1457, 2018. DOI: https://doi.org/10.1007/s10163$\underline{018-0708-7}$ 
REGOA, A. S.; LEITEB, S. A. F.; LEITEB, B. S.; GRILLOC, A. V.; SANTOSA, B. F.. Artificial neural network modelling for biogas production in biodigesters. Chemical Engineering, v.74, 2019. DOI: http://doi.org/10.3303/CET1974005

SANTOS, A. M.; ASSUNÇÃO, G. P.; FIGUEIREDO, A. T.; BARRADO, C. M.. Avaliação da produção de biometano da geração de biogás a partir de dejetos bovinos com diferentes diluições. Revista Processos Químicos, v.13, n.26, p.57-64, 2019. DOI: https://doi.org/10.19142/rpq.v13i26.539

SEIXAS, C. S.; PRADO, D. S.; JOLY, C. A.; MAY, P. H.; NEVES, E. M. S. C.; TEIXEIRA, L. R.. Governança ambiental no Brasil: rumo aos objetivos do desenvolvimento sustentável (ODS) Cadernos Gestão Pública e Cidadania, v.25, n.81, 2020. DOI: https://doi.org/10.12660/cgpc.v25n81.81404

SILVEIRA, S. D. C.; MUNIZ, J. A.; SOUSA, F. A.; CAMPOS, A. T.. Modelos não lineares ajustados à produção acumulada de biogás provenientes de camas sobrepostas de suínos. Revista Agrogeoambiental, v.10, n.3, 2018. DOI: http://dx.doi.org/10.18406/2316-1817v10n320181168

SOARES, C. M. T.; FEIDEN, A.. Balanço de massa de biodigestor modelo bioköhler abastecido com dejetos de bovinocultura de leite. Holos Environment, v.19, n.3, p.441 454, 2019. DOI: https://doi.org/10.14295/holos.v19i3.12337
TAVARES, S. G.; FEIDEN, A.; CORREIA, A. F.; SOARES, C. M. T.; GREGOLIN, M. R. P.. Influência das variações térmicas e climáticas na produção de biogás. Nativa, v.4, p.287-295, 2016. DOI: http://doi.org/10.31413/nativa.v4i5.3219

VALE, A. T.; RESENDE, R.; GONÇALEZ, J. C.; COSTA, A. F.. Estimativa do consumo residencial de lenha em uma pequena comunidade rural do Município de São João D’Aliança - GO. Ciência Florestal, v.13, n.2, p.159-165, 2003. DOI: https://doi.org/10.5902/198050981752

VANDER, L. S.; TEIXEIRA, T.; FRANCISCO, A. C.; PICCININ, C. T.; KOVALESKI, J. L.; PAGANI, R. N.. Vantagens, barreiras e estratégias para economia circular: uma abordagem teórica. Exacta, v.17, p.238-255, 2019. DOI:

https://doi.org/10.5585/ExactaEP.v17n4.8519

VARGAS, B. C.; PAES, J. L.; ANTUNES, B. M. S.; CUNHA, J. P. B.; SANTOS, P. T.; SILVA, A. B.. Thermal energy from biogas generated from cattle manure and sewage sludge.

Theoretical and Applied Engineering, v.4, n.2, p.1-8, 2020. DOI: https://doi.org/10.31422/taae.v4i2.27

WEBER, R.; ZENATTI, D. C.; FEIDEN, A.; TIETZ, C. M. Produção de biogás com relação ao teor de sólidos voláteis dos dejetos de bovinocultura de leite. Revista Brasileira de Energias Renováveis, v.3, p.43-55, 2014. DOI: http://dx.doi.org/10.5380/rber.v3i1.33912

A CBPC - Companhia Brasileira de Produção Científica (CNPJ: 11.221.422/0001-03) detém os direitos materiais desta publicação. Os direitos referem-se à publicação do trabalho em qualquer parte do mundo, incluindo os direitos às renovações, expansões e disseminações da contribuição, bem como outros direitos subsidiários. Todos os trabalhos publicados eletronicamente poderão posteriormente ser publicados em coletâneas impressas sob coordenação da Sustenere Publishing, da Companhia Brasileira de Produção Científica e seus parceiros autorizados. Os (as) autores (as) preservam os direitos autorais, mas não têm permissão para a publicação da contribuição em outro meio, impresso ou digital, em português ou em tradução. 